\title{
Fasting Status at Specimen Collection
}

National Cancer Institute

\section{Source}

National Cancer Institute. Fasting Status at Specimen Collection. NCI Thesaurus. Code C70928.

Indicates whether a specimen obtained from a subject that has abstained from food and possibly water for the prescribed amount of time; or from a subject who has not abstained from food or water. 